\title{
Bate-papo sobre a sexualidade do adolescente no contexto amazônico: um relato de experiência
}

\author{
Chat on adolescent sexuality in the Amazon context: \\ an experience report
}

\author{
Alace da Silva Peres', Amanda Figueiredo Vale de Aquino', Bruna Correa de Mira', \\ Hellen de Paula Silva Rocha', Karine de Paula Martins da Cruz', \\ Paula Carolina Lima de Aviz', Wilker Silva Alves², Ana Caroline Guedes Souza Martins ${ }^{1}$ \\ 'Universidade do Estado do Pará, Belém (PA), Brasil. \\ ${ }^{2}$ Universidade Federal do Pará, Belém (PA), Brasil.
}

\section{RESUMO}

Contextualização: Este trabalho é o resultado da experiência vivenciada por acadêmicos de Enfermagem, durante a disciplina "Povos e Populações Tradicionais da Amazônia", do Curso de Graduação em Enfermagem da Universidade do Estado do Pará, objetivando compreender de que forma a Assistência de Enfermagem alcança a população de adolescentes e jovens quilombolas e ribeirinhos na prevenção da gravidez precoce e de outras temáticas ligadas a saúde do adolescente e do jovem. Descrição da experiência: O estudo iniciou em 2015, precisamente, em novembro com o grupo quilombola em Abacatal, Ananindeua-Pará, posteriormente, no mês dezembro finalizou na comunidade ribeirinha, localizada na ilha de Cotijuba no município de Belém-Pará. Através de metodologias ativas, foram selecionadas palestras e roda de conversa, para abordagem de temáticas sobre a sexualidade, gravidez precoce e métodos contraceptivos, através da educação em saúde, promovendo a troca de experiências e esclarecimentos de dúvidas, além de proporcionar o vínculo profissional com a comunidade e diminuir os riscos em virtude do desconhecimento sobre os temas expostos. Na primeira atividade participaram 15 adultos jovens, enquanto que na segunda atividade participaram 28 adolescentes. Durante as atividades obteve-se como foco o respeito à cultura e suas formas de vivenciar a sexualidade. Considerações finais: Assim percebeu-se a importância da promoção da saúde aos povos e populações tradicionais, visto que necessitam de um "olhar" mais específico frente à dificuldade de acesso aos serviços de saúde e principalmente de informações que estimule a autonomia referente aos cuidados necessários para uma vida saudável.

Recebido: Maio 29, 2016

Aceito: Set. 20, 2016

\section{COMO CITAR ESTE ARTIGO}

Peres AS, Aquino AFV, Mira BC, et al. Bate-papo sobre a sexualidade do adolescente no contexto amazônico: um relato de experiência. Interdisciplinary Journal of Health Interdisciplinary Journal of Health
Education. 2016 Jan-Jul;1(1):58-62 http://dx.doi.org/10.4322/ijhe2016009

\section{CORRESPONDÊNCIA}

Ana Caroline Guedes Souza Martins

Universidade do Estado do Pará

Universidade do Estado do Pará CEP 66063-010, Belém (PA), Brasil. carolguedes.devs@hotmail.com

\section{FONTE DE FINANCIAMENTO}

Recurso próprio.

\section{CONFLITO DE INTERESSE}

Os autores declararam não

haver conflitos de interesse

O estudo foi realizado na Universidade do Estado do Pará, nos municípios de Ananindeua

Todos os autores leram e aprovam a versão final submetida ao Interdisciplinary Journal of Health Education (IJHE).
PALAVRAS-CHAVE: Educação em saúde. Sexualidade. Jovens. Enfermagem.

\begin{abstract}
Contextualization: This work is the result of experience by nursing students during the course "People and the Amazon Traditional Populations" by the Nursing Graduation Program of the Universidade do Estado do Pará, aiming to understand how the nursing care reaches the teenagers population of quilombo and riverside on the prevention of early pregnancy and other topics related to youth health. Experience description: The study began in 2015 , precisely in November with the quilombo Abacatal group, in Ananindeua-Pará, later in the month December finished at the riverside community in Cotijuba Island in the city of Belém-Pará. Lectures and conversation were selected through active methods for thematic approach on sexuality, teenage pregnancy and contraceptives using health education, and promoting the exchange of experiences and questions for clarification, and provide professional link with the community and reduce the risks due to the lack of knowledge about the exposed subjects. Fifteen young adults participated of the first acitivty, while the second activity had the participation of 28 teenagers. During the activities we focused on respect for the culture and ways of living sexuality. Final considerations: Therefore, we realized the importance of health promotion to people and traditional populations, as they need a more specific "look" in light of the difficulty of access health services and especially information that stimulates autonomy regarding the care needed for a healthy life.
\end{abstract}

KEYWORDS: Health education. Sexuality. Teenagers. Nursing. 


\section{Contextualização}

Os povos e populações tradicionais da Amazônia têm despertado interesse no âmbito científico por constituírem-se de modos de vida e necessidades específicas, histórias únicas, além de problemáticas que necessitam ser vistas por profissionais e acadêmicos na área de saúde. Torna-se essencial que o profissional de saúde conheça a realidade do público para que possa planejar ações que os alcancem.

Em virtude do isolamento de seus núcleos populacionais, resultado de difícil acesso e distribuição dispersa destes núcleos, a realidade dessas populações revela uma grande desigualdade de acesso aos serviços públicos de saúde em comparação com as áreas urbanas ${ }^{1}$.

Insere-se, neste contexto, o pré-conceito com as populações tradicionais baseadas em suposições arcaicas que já não tem sentido em tempos atuais. Para que a promoção da saúde seja ferramenta eficaz precisamos, primeiramente, respeitar a autonomia dos habitantes. Assim, aos profissionais de saúde, cabe a seguinte reflexão:

[...] saber que devo respeito à autonomia, à dignidade e à identidade do educando e, na prática, procurar a coerência com este saber, me leva inapelavelmente à criação de algumas virtudes ou qualidades sem as quais aquele saber vira inautêntico, palavreado vazio e inoperante ${ }^{2}$ (p. 36).

Um dos problemas que afeta tanto as populações urbanas, quanto rurais e tradicionais é o aumento da gravidez na adolescência. A fecundidade declinou em todos os grupos etários nos últimos dez anos, as jovens de 15 a 19 anos representaram pela primeira vez uma exceção, com um crescimento de $25 \%$ entre 1991 e 2000 . Vale notar também que vem aumentando a importância relativa desse grupo etário na taxa de fecundidade total. De 9\% em 1980 passa a 14\% em 1991, e em 2000 a fecundidade das jovens de 15 a 19 anos já responde por 20\% do número total de filhos tidos pelas mulheres ao longo de todo o período reprodutivo, ou seja, de 15 a 49 anos. Chama a atenção ainda que a maior parte dessas jovens mães é constituída por solteiras, proporção que veio crescendo no período $1991-2000$, passando de $80 \%$ para $94 \%{ }^{3}$.

Para a resolução deste problema torna-se fundamental a implantação de ações junto ás políticas públicas, que promovam diálogos e vínculos, em parcerias com escolas e famílias, de forma a proporcionar o acesso à informação sobre o uso de anticoncepcionais e prevenção da gravidez na adolescência. As parcerias são importantes, pois considera-se que o adolescente pouco busca os serviços ofertados pelas Unidade de Saúde ${ }^{4}$.

Essa problemática gerou a reflexão dos pesquisadores quanto ao tema e diante disto, o objetivo deste estudo é entender de que forma a assistência de Enfermagem alcança as populações tradicionais quanto à prevenção da gravidez precoce e na educação sexual.

Assim, fica evidente a necessidade de se entender estas comunidades a partir de uma associação de suas particularidades como povo e as necessidades peculiares provenientes destas, e atendê-las, garantindo, desta forma, que os preceitos do SUS sejam empregados nestes grupos.

\section{Descrição da experiência}

Trata-se de um relato de experiência sobre a vivência de acadêmicos do Curso de Graduação em Enfermagem da Universidade do Estado do Pará, durante a disciplina "Povos e Populações Tradicionais da Amazônia", ocorrida em dois momentos no ano de 2015: em novembro na Comunidade Quilombola de Abacatal, em Ananindeua-Pará e em dezembro, na comunidade Ribeirinha de Cotijuba, em Belém-Pará. O público-alvo foram os adolescentes e jovens que aceitaram participar do estudo.

O método foi desenvolvido através das tecnologias ativas, que selecionou a roda de conversa e o lúdico para tratar sobre a sexualidade, gravidez precoce e exposição 
sobre o uso seguro de métodos contraceptivos, utilizando-se dos acervos disponíveis nas bases de dados em saúde para fortalecer a fala sobre a temática no momento da abordagem com o público - alvo. O tema "Puberdade, sexualidade e gravidez na adolescência" foi uma sugestão feita pela própria comunidade, visto ser um problema que a comunidade tem enfrentado atualmente.

A primeira atividade foi realizada em uma comunidade quilombola com forte influência urbana, localizada na Estrada Santana do Aurá, á $8 \mathrm{~km}$ do centro de Ananindeua, em que residem 53 famílias. Segundo informações de líderes da comunidade, as terras foram herdadas quando o senhor de escravos, que ali habitava reconheceu três filhas que teve com uma escrava. Porém, suas terras só foram reconhecidas a partir de maio do ano de 1999. A história de resistência da comunidade fica evidente com os relatos orais transmitidos às gerações.

A segunda atividade ocorreu à Ilha de Cotijuba, vinculada ao Distrito de Outeiro. O nome remete aos primeiros moradores Tupinambás, e sua importância histórica também é notada pelas ruínas de um antigo educandário. Sua localização se insere em um conjunto de Ilhas do Extremo Oeste de Belém. Segundo a AMICIA (Associação dos Moradores da Ilha de Cotijuba e Ilhas Adjacentes) a população no ano de 2008 era de 4.000 habitantes.

O transporte até a ilha é de barco, variando entre 45 minutos à uma hora. Na ilha percebe-se não só charretes, cavalos e bicicletas, como também um número de motos crescente. Quanto aos serviços de saúde, a ilha possui uma equipe de Estratégia de Saúde da Família e uma Unidade Básica de Saúde, onde se prestam serviços de obstetrícia, consultas, além de exames e urgência e emergência. Existe também a ambulancha, que realiza o transporte dos casos mais complexos até a sede do município de Belém.

Na primeira atividade houve a participação de 15 adultos jovens, enquanto que na segunda atividade participaram 28 adolescentes. Iniciou-se as rodas de conversa falando inicialmente sobre os aspectos físicos e biológicos das mudanças ocorridas no período da puberdade e orientação sexual, dificuldade na comunicação com os pais, demonstração de como se utiliza os métodos anticoncepcionais, em que foi realizada a demonstração da correta colocação do preservativo masculino e feminino, bem como a distribuição destes insumos para o público, porém o foco maior foi a gravidez na adolescência.

Houve uma boa aceitação pelo público-alvo, pois nesse sentido, é possível destacar a participação dos presentes, seja por meio de questionamentos, visando sanar dúvidas, principalmente no tocante aos métodos contraceptivos, seu uso e eficácia, como também exposição de experiências particulares relacionadas à temática, tornando o diálogo ainda mais rico e relevante tanto aos acadêmicos, quanto aos componentes da comunidade.

Em virtude das comemorações do Dia da Consciência Negra, grande parte da comunidade encontrava-se reunida na escola situada dentro dos limites do Abacatal. Durante a celebração, houve momentos em que foram ressaltadas falas a respeito das lutas que a população enfrenta, no intuito de manter suas características e modo de vida próprios, bem como a importância de ações de educação em saúde, como as que estavam sendo promovidas pelos acadêmicos e docente.

\section{Resultados e discussões}

Observou-se que a faixa etária predominante durante a abordagem na Comunidade Quilombola foi a de adultos e jovens, de 20 a 30 anos, além de outros grupos como os pais e adolescentes que já são mães.

Dentre os relatos feitos pelos pais a primeira problemática está na dificuldade do vinculo da equipe de saúde com os adolescentes, haja vista a distância que entre a comunidade e as unidades de saúde não contribui para esta aproximação, ficando a 
escola como principal meio de informação, geralmente, sobre temas que envolvam a sexualidade e outros assuntos.

Ainda durante a ação os pais mencionaram início sexual precoce e que a primeira gestação foi na adolescência, sendo uma situação comum a gestação na adolescência. O grupo manifestou bastantes dúvidas relacionadas ao uso do preservativo masculino, principalmente, e a pílula anticoncepcional.

Em Cotijuba, a palestra sobre sexualidade ocorreu na Escola Bosque da ilha, onde o público alcançado estava na faixa etária de 10-13 anos de idade. No início, os temas abordados arrancaram dos espectadores risos e a timidez foi percebida. Foi utilizada uma linguagem adequada para fácil entendimento, porém não excluindo os termos técnicos corretos. Durante a demonstração do uso do preservativo masculino e feminino, o público permaneceu mais atento. Na sala de aula encontrava-se uma adolescente grávida, então foi necessário incluir na conversa uma abordagem frisando que a gravidez precoce muda a rotina da jovem mãe, mas que não é capaz de excluir os sonhos, principalmente aqueles referentes a vida social e profissional, bem como a importância da família neste momento.

Durante a troca de informações nas atividades frisou-se a importância da família na educação sexual dos filhos e o quanto é benéfico a questão não ser tratada como tabu. Os participantes deixaram o ambiente rico de relatos onde a assistência de Enfermagem pode incluir-se orientando a respeito de cada dúvida.

A temática das Doenças Sexualmente Transmissíveis não foi abordada amplamente nesta roda de conversa, pois o intuito era entender de que forma os temas sexualidade, orientação sexual, puberdade, gravidez precoce e métodos contraceptivos eram conhecidos pelo público-alvo. Embora tenham surgido algumas perguntas sobre o tema e que foram devidamente respondidas, mas procurando não perder o foco do objetivo esperado.

Pode-se dizer que os resultados das ações desenvolvidas foram satisfatórios, até mesmo superando as expectativas de seus elaboradores, uma vez que a aceitação, participação e discursos vieram a acrescentar e tornar a roda de conversa construtiva, enriquecedora e significativa.

\section{Considerações finais}

Enquanto acadêmicos de enfermagem, acreditamos que a puberdade, por ser uma fase muito importante e complexa no desenvolvimento do ser humano, por trazer inúmeras mudanças biológicas, físicas, psicológicas e sociais, exige que o profissional de enfermagem seja preparado durante a vida acadêmica para lidar com as dúvidas deste grupo, de forma a melhor orientá-los quanto à saúde reprodutiva e sexual.

Devido à sexualidade nesta fase encontrar-se reprimida pela família e/ou associadas a costumes, religião ou fatores externos que transformam este momento em um tabu. Faz-se importante trabalhar não apenas com os jovens, mas também com toda a sociedade, nas mais diversas instituições. É necessário que a família esteja preparada para educar os filhos, sem medos ou restrições, fortalecendo o vínculo e favorecendo a amizade entre seus componentes.

Os povos e populações tradicionais necessitam de um "olhar" mais específico frente à dificuldade de acesso aos serviços de saúde que atendam o adolescente na prevenção de gravidez e paternidade precoce, no tratamento de doenças sexualmente transmissíveis, no planejamento para uma futura concepção e assistência à maternidade e ao bebê. Ter esta experiência durante a academia proporcionou maior segurança quanto à abordagem as populações tradicionais, bem como tornou possível conhecer suas peculiaridades.

A partir da experiência, ficou evidente que a comunidade luta todos os dias pela garantia de sua existência e direitos, e como não poderia deixar de ser, também por um serviço de saúde de qualidade, que siga efetivamente os preceitos propostos pelo SUS. 
Assim, tal vivência mostrou-se de extrema relevância na formação dos acadêmicos, uma vez que o contato com uma parcela tão singular da população que possui grande dificuldade em ter suas demandas atendidas abre precedentes para novas reflexões a respeito do tipo de atenção que prestarão no futuro, durante a realização do exercício profissional ao qual se dispõem.

Nas duas atividades, a escola foi o espaço ideal por ser um local acolhedor, que propicia o diálogo dentro das comunidades, por ser um espaço de convivência social, além de que tornou-se imprescindível na divulgação de informações sobre saúde a população alvo do estudo.

Os trabalhos de orientação sexual realizados tanto por profissionais que atuam na escola como por profissionais da área da saúde são fundamentais para o enfrentamento de problemas sociais individuais e coletivos que afetam os adolescentes. Os projetos político pedagógicos das escolas precisam contemplar esta especificidade, trazendo benefícios para suas vidas, pois estão em uma fase peculiar de desenvolvimento, tanto emocional quanto físico e social.

Assim, os programas orientação sexual desenvolvidos nas escolas não podem limitar-se à prevenção de DSTs e gravidez. Eles precisam ser abrangentes e devem trazer para a discussão aspectos gerais da sexualidade humana, que constituem a base para uma vida sexual saudável e prazerosa, partindo principalmente das demandas trazidas pelos jovens, incentivando que o mesmo seja o protagonista na aquisição de novos conhecimentos.

Ainda, é imprescindível salientar que os adolescentes são detentores do poder de escolha, mas precisam estar cientes de suas responsabilidades, pois as consequências de seus atos poderão interferir em todo o seu projeto de vida.

A metodologia utilizada, através da educação em saúde, promoveu a troca de experiências e esclarecimentos de dúvidas, o que proporcionou vínculo profissional-comunidade e minimizou os riscos em virtude do desconhecimento sobre os temas expostos e desmitificação. Durante as atividades obteve-se como foco o respeito à cultura e suas formas de vivenciar a sexualidade.

Além dos serviços rotineiros oferecidos nos serviços de saúde para a população de forma geral, que abrangem superficialmente os adolescentes, há necessidade imediata de planejar e implementar ações de saúde, personalizadas para esta clientela. Contudo, percebe-se ainda a carência de políticas de saúde e educação voltadas para os adolescentes, sobretudo aos que pertencem a comunidades tradicionais com o foco na Atenção Primária em Saúde e resgate desta clientela para promoção da saúde e melhoria do acesso aos serviços. Por sua vez, esta pauta precisa estar inclusa no planejamento dos gestores e das próprias equipes de Estratégia de Saúde da Família, bem como estar inserida no currículo acadêmico.

\section{Referências}

1. Silva RF. Valores culturais que envolvem o cuidado materno ribeirinho: subsídios para a enfermagem [dissertação]. Rio de Janeiro: UNIRIO; 2009.

2. Freire P. Pedagogia da autonomia: saberes necessários à pratica educativa. São Paulo: Paz e Terra; 1996.

3. Abramovay M. Juventude e sexualidade. Brasil: UNESCO. Brasília; 2004.

4. Fiedler MW, Araújo A, Souza MCC. A prevenção da gravidez na adolescência na visão de adolescentes. Texto Contexto Enferm. 2015;24(1):30-7.

\section{Contribuição dos autores}

Alace da Silva Peres, Amanda Figueiredo Vale de Aquino, Bruna Correa de Mira, Hellen de Paula Silva Rocha, Karine de Paula Martins da Cruz e Paula Carolina Lima de Aviz: Elaboração e desenvolvimento da atividade educativa, análise dos dados, discussão e conclusão. Wilker Silva Alves: Análise dos dados, discussão, conclusão e formatação do trabalho para publicação. Ana Caroline Guedes Souza Martins: Orientadora da atividade. 